\title{
The Immune System in Irritable Bowel Syndrome
}

\author{
Giovanni Barbara, ${ }^{*}$ Cesare Cremon, Giovanni Carini, Lara Bellacosa, Lisa Zecchi, Roberto De Giorgio, Roberto Corinaldesi \\ and Vincenzo Stanghellini
}

Department of Clinical Medicine and Center for Applied Biomedical Research University of Bologna, Bologna, Italy

The potential relevance of systemic and gastrointestinal immune activation in the pathophysiology and symptom generation in the irritable bowel syndrome (IBS) is supported by a number of observations. Infectious gastroenteritis is the strongest risk factor for the development of IBS and increased rates of IBS-like symptoms have been detected in patients with inflammatory bowel disease in remission or in celiac disease patients on a gluten free diet. The number of $T$ cells and mast cells in the small and large intestine of patients with IBS is increased in a large proportion of patients with IBS over healthy controls. Mediators released by immune cells and likely from other non-immune competent cells impact on the function of enteric and sensory afferent nerves as well as on epithelial tight junctions controlling mucosal barrier of recipient animals, isolated human gut tissues or cell culture systems. Antibodies against microbiota antigens (bacterial flagellin), and increased levels of cytokines have been detected systemically in the peripheral blood advocating the existence of abnormal host-microbial interactions and systemic immune responses. Nonetheless, there is wide overlap of data obtained in healthy controls; in addition, the subsets of patients showing immune activation have yet to be clearly identified. Gender, age, geographic differences, genetic predisposition, diet and differences in the intestinal microbiota likely play a role and further research has to be done to clarify their relevance as potential mechanisms in the described immune system dysregulation. Immune activation has stimulated interest for the potential identification of biomarkers useful for clinical and research purposes and the development of novel therapeutic approaches.

(J Neurogastroenterol Motil 2011;17:349-359)

Key Words

Abdominal pain; Immune system; Irritable bowel syndrome; Mast cells

\section{Introduction}

The irritable bowel syndrome (IBS) is characterized by abdominal pain/discomfort and changes in bowel habit which are not associated with organic causes. IBS represents one of the most common functional gastrointestinal (GI) disorders with an overall prevalence estimated around 10\%-15\% in Europe and the
United States. ${ }^{1}$ The pathophysiology of IBS is not completely understood, but believed to be the consequence of dysregulation of the brain-gut axis with both central and peripheral mechanism involved. Central mechanisms include anxiety, depression and somatisation while peripheral dysfunction is characterized by changes in gut motility and secretion as well as visceral hypersensitivity. ${ }^{2}$ Cellular and molecular abnormalities in mucosal enteroendocrine system as well as mucosal and systemic immune re-

Received: July 9, 2011 Revised: July 21, 2011 Accepted: July 23, 2011

(c) This is an Open Access article distributed under the terms of the Creative Commons Attribution Non-Commercial License (http://creativecommons. org/licenses/by-nc/3.0) which permits unrestricted non-commercial use, distribution, and reproduction in any medium, provided the original work is properly cited.

*Correspondence: Giovanni Barbara, MD

Department of Internal Medicine and Gastroenterology, S. Orsola-Malpighi Hospital - Via Massarenti, 9 - Building \# 5, I-40138 Bologna, Italy

Tel: +39-051-636-4103, Fax: +39-051-34-5864, E-mail: giovanni.barbara@unibo.it

Financial support: This work was supported by the Italian Ministry of Education, University and Research (No. 2002052573 [G.B., V.S., R. De G. and R.C.] and No. 2007Z292XF [G.B. and R.C.]), from the University of Bologna (G.B., R. De G. and R.C.). G.B. is a recipient of grants from Conflicts of interest: None. "Fondazione Cassa di Risparmio di Bologna", Bologna, Italy and IMA S.p.A., Bologna, Italy. 


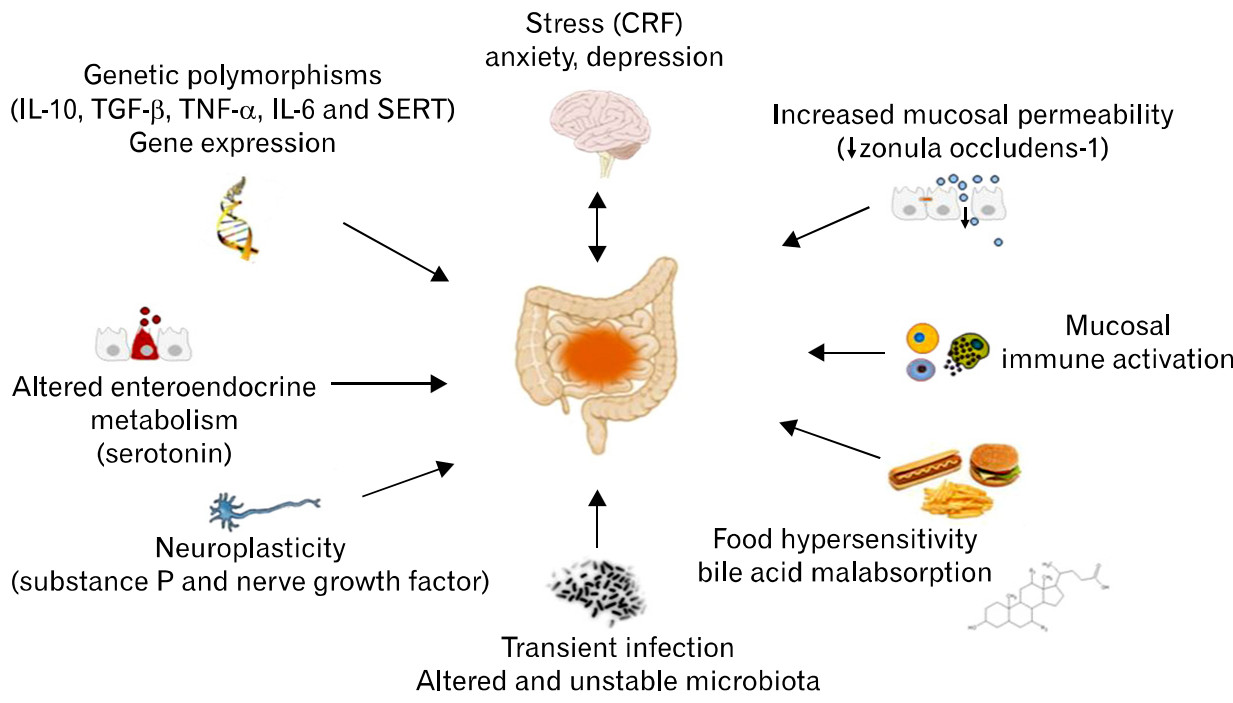

Figure 1. Putative biological factors involved in the pathophysiology of irritable bowel syndrome. CRF, corticotropin releasing factor; SERT, serotonin reuptake transporter. sponses have been postulated to participate in the brain-gut dysfunction. ${ }^{3}$ A schematic representation of novel biological factors involved in IBS pathophysiology is provided in Figure 1.

Inflammation refers to the response of the immune system to injury and is characterized by the classical signs of redness (rubor), heat (calor), swelling (tumor) and pain (dolor) which have been originally described by the Roman encyclopedist Celsus $^{3}$ (25 BC-45 AD) in the famous ancient book De Medicina. Rudolf Virchow in 1858 added to this definition the concept of functio laesa, reflecting functional impairment of the affected organs or tissues. ${ }^{4}$ These pathological factors are determined by a cascade of biochemical events leading to the movement of leukocytes (frequently granulocytes) from the blood into the tissue and the release of biological products (eg, proinflammatory cytokines) determining processes of tissue damage and subsequent healing. Classical examples of intestinal inflammatory diseases include infectious gastroenteritis, caused by invasive pathogens such as Shigella, Salmonella and Clostridium difficile, idiopathic chronic inflammatory bowel diseases (IBD) including Crohn's disease and ulcerative colitis, radiation enteropathy or acute diverticulitis. Clearly, the typical aspects of overt inflammation or mucosal architecture distortion seen in these disorders are absent in patients with IBS. However, the application of quantitative assessment and the use of molecular biology has revealed the presence of mild activation of the immune system both locally (ie, intestinal mucosa) or systemically (ie, plasma, serum and peripheral blood mononuclear cells). Yet, conflicting results have been reported, probably reflecting the large overlap of data with healthy controls and the wide heterogeneity and protean symptom manifestations of the IBS population. The argument is whether these mild immune abnormalities represent epiphenomena or are of relevance for the aberrant bowel function and symptom manifestation. Importantly, recent studies have shown that mucosal or luminal mediators obtained from patients with IBS, but not controls, evoked abnormal functional responses in enteric and sensory nerves and disrupted intestinal barrier integrity of recipient laboratory animals, isolated rodent ${ }^{5-7}$ or human tissues ${ }^{8}$ or cell culture. ${ }^{9}$ Most of these effects were ascribed to molecules of immune origin. A schematic figure representing this translational approach is provided in Figure 2. These results taken in conjunction with data showing correlations with symptoms and initial evidence of some beneficial effects of immunomodulatory agents ${ }^{10}$ support a contributing role of the immune system in the pathogenesis of at least a large subgroup of patients with IBS.

In the following review, we report on the rapidly evolving field on the potential pathogenetic role of the immune system in patients with IBS as well as clinical and therapeutic implications of these findings.

\section{The Clinical Scenarios Linking Immune Activation to Irritable Bowel Syndrome -}

The implication of intestinal immune activation in the pathogenesis of IBS is supported by at least 2 key clinical observations, namely: (1) the development of IBS symptoms in subjects involved in an episode of acute infectious gastroenteritis (the so called post-infectious IBS) and (2) the reported higher prevalence of IBS-like symptoms in patients with IBD in remission, 
A

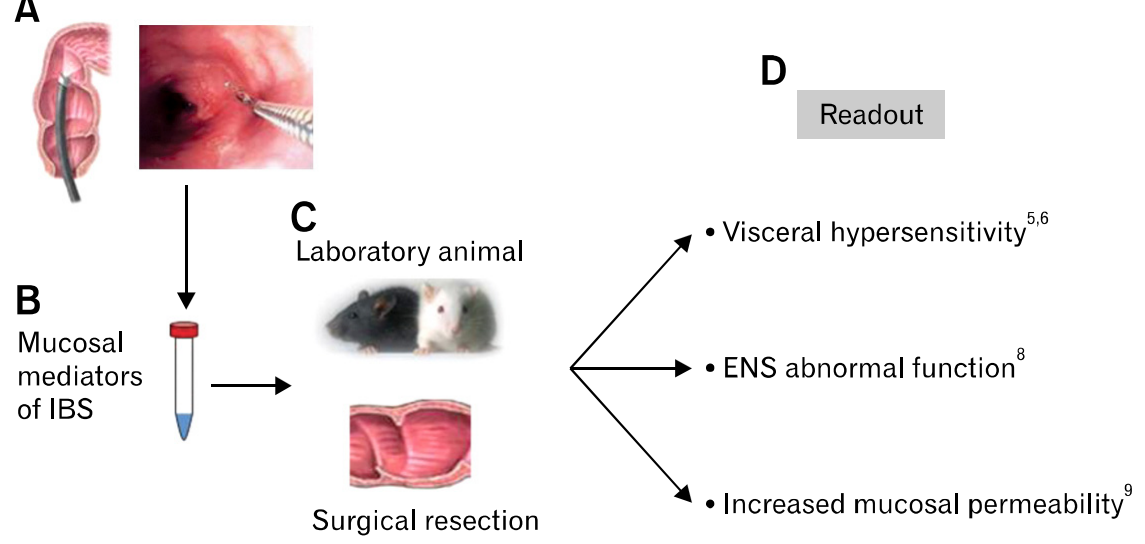

Reponses inhibited by antagonists of immune factors (eg, proteases, histamine and serotonin)

Figure 2. Schematic representation of translational approach to assess the impact of mucosal bioactive factors on sensory afferents, enteric nerves and epithelial permeability. (A) Mucosal biopsies are taken from the mucosa of descending colon. (B) Mucosal spontaneous release of bioactive factors is obtained, collected and stored. (C) Laboratory animals and surgical resection specimens of colon are used as recipient for the assessment of the impact of isolated mediators. (D) Readout of visceral sensitivity, sensory nerve discharge, enteric nervous system function and mucosal permeability can be assessed in the presence or absence of specific pharmacologic antagonists/inhibitors to identify specific molecules involved. IBS, irritable bowel syndrome; ENS, enteric nervous system. Adapted from Cenac et al, ${ }^{5}$ Barbara et al, ${ }^{6}$ Buhner et al $^{8}$ and Piche et al. ${ }^{9}$

microscopic colitis or celiac disease on a gluten free diet.

\section{Post-Infectious Irritable Bowel Syndrome-}

Following a bout of infectious gastroenteritis, a small but significant proportion of subjects go on to develop post-infectious IBS, dyspepsia or both (for review, see reference ${ }^{11}$ ). A recent systematic review and meta-analysis identified that the pooled incidence for IBS development after infectious gastroenteritis was about $10 \%$ (95\% CI, 9.40-85.6). ${ }^{12}$ Recent studies focused on a waterborne outbreak of gastroenteritis involving around half of the population of the small town of Walkerton in Canada. Residents of this community developed gastroenteritis as a consequence of accidental contamination of the municipal water supply with Escherichia coli O157:H7 and Campylobacter jejuni. Two years later, $36 \%$ of those infected developed IBS. Similarly to the previous smaller sample size reports, risk factors for the development of IBS symptoms included: female gender and the severity of the initial illness, (ie, weight loss, bloody diarrhea and long duration of the infectious episode). ${ }^{13,14}$ Previous work also demonstrated the importance of psychological co-morbidity for the development of post-infectious IBS. ${ }^{15}$ The mechanisms underlying the persistence of symptoms remain poorly defined, but may include genetic factors, particularly related polymorphisms for genes involved in pro-inflammatory cytokine production (IL-6) and host-bacteria interactions (one of the bacterial recognition receptor, toll-like receptor 9) as well as molecules involved in the control of mucosal permeability (tight junctions). ${ }^{16}$ Intestinal tissue analysis identified the persistence of low-grade immune activation and enteroendocrine abnormalities. Spiller et $\mathrm{al}^{17}$ showed increased numbers of intraepithelial lymphocytes, lamina propria $\mathrm{T}$ cells, calprotectin-positive macrophages and enteroendocrine cells which failed to decline in patients who develop post-infectious IBS. Others have reported an increased number of mast cells in the terminal ileum, ${ }^{18}$ while the number of these cells was normal in the rectum. ${ }^{18,19}$

\section{Irritable Bowel Syndrome-Like Symptoms in Patients With Inflammatory Bowel Diseases, Microscopic Colitis and Celiac Disease}

IBS-like symptoms develop in about $50 \%$ of patients with microscopic colitis ${ }^{20}$ and in $33 \%-57 \%$ of patients with ulcerative colitis or Crohn's disease in remission. ${ }^{21,22}$ These figures are substantially higher than the expected prevalence of IBS in the general population and support the assumption that human lowgrade mucosal inflammation could play a role on IBS symptom 
development. Interestingly, IBS-like symptoms in patients with IBD were significantly associated to the presence of psychological impairment and poor quality of life. ${ }^{22,23}$ IBD is thought to result from inappropriate and ongoing activation of the mucosal immune system driven by the intestinal microbiota. This aberrant response is facilitated by defects in both the barrier function of the intestinal epithelium and the mucosal immune system, which are likely influenced by genetic factors. ${ }^{24}$ As our understanding evolves, it appears that many of these mechanisms are common to IBS and IBD although obvious quantitative-qualitative differences exist.

Similarly to IBD and microscopic colitis a high rate of IBS-like symptoms has been reported in patients with celiac disease living on a gluten free diet and after apparent resolution of mucosal damage and immune activation. ${ }^{25,26}$ Whether a mild immune activity in the mucosa and minimal changes in mucosal permeability are involved in the symptom persistence in these patients remains to be determined.

\section{Systemic Immune Activation}

Although IBS is characterized mainly by changes in bowel function, it shows many systemic features with frequent association with psychological factors and co-morbidities with other GI (eg, functional dyspepsia) and extra-intestinal (eg, migraine, fibromyalgia and interstitial cystitis) disorders. ${ }^{27}$ Interestingly, mild infiltration of immune cells interacting with tissue innervation has been described in the gut of patients with IBS as well as in some co-morbid conditions, including fibromyalgia, ${ }^{28}$ interstitial cystitis $^{29}$ and vulvar vestibulitis. ${ }^{30}$

Subsets of patients with IBS show evidence of abnormal systemic immune responses. In particular, a high proportion of patients displays an increased frequency of circulating cytotoxic $\mathrm{CD} 8+\mathrm{T}$ cells expressing the gut homing integrin $\alpha 4 \beta 77^{31}$ This well correlates with increased CD8 $+\mathrm{T}$ cells in the lamina propria and epithelium (intraepithelial lymphocytes) in patients with nonspecific and post-infectious IBS. ${ }^{17,31-33}$ On the other hand, circulating CD4 $+\mathrm{T}$ cells seem to play no role since CD4+/ $\mathrm{CD} 25+$ regulatory $\mathrm{T}$ cells, which are known to be involved in suppressing inflammation, showed similar frequencies in IBS patients and controls. ${ }^{34}$ The role of $\mathrm{B}$ cells and relative antibody production is controversial. An increased $\mathrm{IgG}+\mathrm{B}$ cell frequency has been reported in the blood of IBS patients, ${ }^{35}$ which is in keeping with the detection of circulating antibodies to bacterial flagellin in IBS. ${ }^{36}$ However, 2 studies reported that the numbers of mucosal B cells were unchanged in IBS patients vs controls. ${ }^{32,37}$

Overall, the currently available data show increased levels of plasma/serum pro-inflammatory cytokines, including IL-1 $\beta$, TNF- $\alpha$, IL-6 and IL- $8,{ }^{38,39}$ as well as higher release of similar patterns of cytokines from resting or stimulated peripheral blood mononuclear cells ${ }^{40,41}$ in patients with IBS compared with healthy controls. Interesting data suggest that, besides proinflammatory cytokines, the systemic immune response may be driven by the release of Th2 cytokines, including IL- 5 and IL-13 by polyclonically stimulated blood T cells. ${ }^{42} \mathrm{Th} 2$ cytokines are involved in the stimulation of certain types of immune activation seen in allergic disorders such as asthma and atopic dermatitis and in parasitic infections.

\section{Mucosal Immune Activation}

The intestinal mucosa generally contains an increased number of immunocytes (mainly T cells and mast cells) along with alteration of gene expression of several components of the host mucosal immune response to microbial pathogens. ${ }^{43}$ Most studies reported increased infiltration of immune cells in the rectum ${ }^{24}$ and colon, ${ }^{33}$ however, increased mast cell numbers ${ }^{44,45}$ and intraepithelial lymphocytes ${ }^{46}$ have also been detected in the ileum and duodenum, indicating the involvement of the small bowel. The intestinal mucosa produces also higher amounts of different mediators including proteases, histamine and prostaglandins, but likely not proinflammatory cytokines. ${ }^{5,6,47,48}$ Comparative studies demonstrated that the magnitude of the immune infiltrate detected in patients with IBS was markedly lower than that of active or quiescent ulcerative colitis. ${ }^{32}$ However, the number of immune cells of IBS overlapped with that detectable in patients with microscopic colitis, ${ }^{32}$ even if only a minority $(1.5 \%)$ of patients fulfilling Rome II criteria for IBS satisfied stringent criteria for microscopic colitis. $^{49}$

Mast cells, a key component of the innate immune system, are considered as sentinels strategically located at the interface between the host and the external environment. They can be activated by both the cross-link of $\operatorname{IgE}$ (allergic reactions type I) and non classical pathways including neuro-hormonal stimulation, particularly following stressful experience. ${ }^{50}$ Upon activation, mast cells release a number of biologically active substances contained in their granules, including histamine, serotonin and proteases. They can also release cytokines and membrane-derived arachidonic acid metabolites including prostaglandins and leukotriens. ${ }^{50}$ There are several reports indicating that mast cell 
counts are increased in the mucosa of both the large and small intestine in patients with IBS compared with controls. ${ }^{32,37,45,51,52}$ Ultrastructural studies showed increased features of activation of mast cells including higher proportion of cells with of clearing of single granules and labyrintic arrays. ${ }^{47}$ This well correlates with higher release of the mast cell mediators histamine and proteases. ${ }^{6,47}$ Although histamine is specific for mast cells, increased production of proteases in the intestine may also originate from luminal and mucosal associated bacteria. ${ }^{53}$ There is also an infiltration of cells of the adaptive immunity in IBS as demonstrated by significantly higher counts of mucosal CD3,$+ \mathrm{CD} 4+$ and CD8 + T cells compared with controls. ${ }^{17,31-33,51}$ In addition, increased mucosal staining of the CD25 marker in the colonic mucosa suggests increased activation of $\mathrm{T}$ cells. ${ }^{33} \mathrm{We}$ found that roughly $50 \%$ of IBS patients showed an increased mucosa cellularity suggesting the potential relevance of immune mechanisms only in a subset of patients. ${ }^{32}$ However, the exact subgroups of patients showing these abnormalities remain ill defined. In our previous studies we found that mast cell increase was gender dependent. Compared to male IBS, female patients showed greater numbers of mast cells but lower numbers of CD3 + and $\mathrm{CD} 8+\mathrm{T}$ cells. ${ }^{32,47}$ These findings are in keeping with the knowledge that the immune system differs between males and females. ${ }^{54}$ The correlation of immune cell infiltration with patients' bowel habit is controversial. A similar degree of mast cell infiltration was found in patients with predominant diarrhea or constipation $^{32,47,51,52}$ while other studies have reported that immune cell counts were higher in patients with diarrhea. ${ }^{44,45}$

Although a number of studies support the evidence of immune activation in different sites along the GI tract in IBS, negative studies have also been published. For example, Cenac et al, ${ }^{5}$ failed to find increased number of mast cells in the rectum or ascending colon of patients with IBS as compared with healthy controls. Similarly, MacSharry et $\mathrm{al}^{48}$ found that the levels of IL-1 $\beta$, TNF- $\alpha$ and IL-6 measured in biopsy samples were comparable between patients and controls. The mentioned wide overlap with healthy controls, different methodological approaches across studies (eg, patient and healthy control selection, laboratory methods and bowel preparation) and geographical differences may, at least in part, explain these apparently contradictory results. Site of sampling may also be considered as another factor in the interpretation of the negative studies. For example, O'Sullivan et al, ${ }^{37}$ detected increased mast cells numbers in the cecum, irrespective of bowel habit, but not in other sites of sampling along the colon or rectum.

\section{Impact of Immune Activation on Gastrointestinal Sensorimotor Function and Intestinal Barrier}

There are possible implications of immune system activation in the pathophysiology of IBS (Fig. 1). As reported in detail above, mast cells have been the focus of several studies evaluating putative mechanisms underlying IBS symptom generation. ${ }^{47}$ Mast cells are found in close proximity to nerves supplying the gut mucosa. This close spatial association is considered a key feature underlying the crosstalk between the immune and nervous system in the gut. ${ }^{55} \mathrm{We}$ and others have previously demonstrated that mast cells of IBS patients were located in closer vicinity to mucosal innervation, suggesting that mediators released by mast cells, including tryptase and histamine, have an increased potential to affect neural function. ${ }^{47,56}$

The biological significance of mast cells and mediators released from the intestinal mucosa of patients with IBS for gut sensory-motor function has been assessed. Mediators have been isolated and transferred to whole or isolated tissues from laboratory animals (eg, rat and mouse) or to surgically removed intestinal samples (Fig. 2). ${ }^{5,6,8,57}$ Mucosal mediators of IBS patients, but not controls, evoked increased activation of sensory pain pathways when applied to isolated intestinal preparations from the rat. ${ }^{6}$ Supernatants from colonic biopsies caused somatic and visceral hyperalgesia and allodynia when applied to mice. ${ }^{5}$ In addition, supernatants obtained from colonic biopsies of patients with IBS evoked abnormally high activation of human enteric neruons, via histamine, serotonin and protease-dependent mechanisms, suggesting the implication of mast cells as well as other potential cell components. ${ }^{8}$ Serine proteases released by mast cells, and possibly also from intestinal bacteria, have been studied in further detail. Proteases are markedly increased in the mucosa of patients with IBS $^{5,47,58}$ and may act as signaling pain molecules via the activation of protease activated receptors (PAR) located on intestinal nerves conveying pain stimuli to the brain. ${ }^{5,47,59}$ Trypsin and tryptase nociceptive effects evoked in mice were reduced by serine protease inhibitors as well as by antagonist of the receptor PAR2 or in PAR2-deficient mice. ${ }^{5}$ These studies established that released proteases stimulate sensory neurons and generate pain sensitivity through the activation of PAR2.

Another particularly active field of investigation relates to the potential effect of biological products released by the intestinal mucosa and/or luminal factors on the integrity of the intestinal 
barrier. This interest has been generated by previous evidence of increased intestinal permeability in patients with post-infectious and diarrhea-predominant IBS. ${ }^{9,13,17}$ Transfer of fecal supernatants from patients with diarrhea-predominant IBS evoked increased mucosal permeability in mice ${ }^{7}$ and mucosal factors obtained from IBS evoked epithelial barrier dysfunction and tight junction disruption in isolated epithelial monolayers. ${ }^{9}$ The effect of fecal supernatants on epithelial barrier were absent in mice lacking PAR-2. ${ }^{7}$ These results suggest that mucosal or luminal mediators impact negatively on mucosal barrier by increasing epithelial permeability through a protease, PAR-2-dependent pathway and open new avenues for therapeutic intervention.

\section{What Causes Immune Activation in Irritable Bowel Syndrome?}

The causes of intestinal immune cell activation in IBS patients remain unclear. A number of mechanisms has been postulated, including undetected food allergies, ${ }^{60}$ stress, ${ }^{61}$ previous infections (post-infectious IBS), ${ }^{11}$ abnormal microbiota, ${ }^{62}$ bile acid malabsorption $^{63}$ and increased intestinal permeability. ${ }^{9}$

There is considerable evidence linking central nervous system mechanisms with symptom perception in patients with IBS. Accordingly, IBS symptoms are sometimes exacerbated by stress and can be associated with psychological co-morbidities such as anxiety, depression, hypochondiasis and phobic disorders. ${ }^{64}$ The mechanisms through which the brain affects bowel physiology in patients with IBS are not completely understood, but may involve bidirectional interactions in the brain-gut-axis through changes in neurotransmitter release affecting motor, endocrine, autonomic and immune function. ${ }^{65}$ Corticotropin-releasing factor (CRF) is a key mediator of stress response in the brain-gut-axis in IBS (Fig. 1). ${ }^{61,66}$ Activation of CRF-receptor 1 in the periphery causes a proinflammatory response and pro-nociceptive responses. $\mathrm{CRF}$ and related receptors represent an interesting potential mechanism of brain-gut axis dysfunction in IBS an exciting potential therapeutic target in these patients which deserve further attention. $^{67}$

The contribution of genetic polymorphysms to immune activation remains elusive and yet controversial. Data indicate that larger proportions of IBS patients show the high producing heterozygous TNF- $\alpha$ G/A polymorphism at position- $308{ }^{68}$ Significantly reduced frequencies of the high producer genotype for IL-10 have been also described, suggesting a specific genetic predisposition to inflammation. ${ }^{69}$ However, the latter finding has not been confirmed in a more recent study. ${ }^{6}$

As previously stated enteric infection is now a recognized risk factor for the development of post-infectious IBS. It has been postulated that these patients are unable to efficiently suppress the initial immune response with persistence of mildly increased mucosal infiltration of T cells. ${ }^{15,17,18}$

The epithelial lining could be a target of the immune activation, with proteases contributing to reduced expression of molecules involved in tight junction function (ie, zonula occludens-1) and consequent increased epithelial permeability. ${ }^{9}$ On the other hand, increased permeability could participate to ongoing intestinal immune stimulation by uncontrolled exposure of the lamina propria to an abnormal antigenic load. ${ }^{70}$

Several lines of evidence suggest the contribution of intestinal microbiota in the pathophysiology of IBS including: (1) presence of antibodies against flagellin (a component of indigenous bacteria inhabiting the human gut), in patients' subgroups ${ }^{36} ;(2)$ improvement of symptoms following modulation of gut microbiota $^{71}$ with probiotics ${ }^{72}$ and non-absorbable antibiotics ${ }^{73}$; and (3) microbiota instability over time as well as significant differences in bacterial composition (mainly reduced lactobacilli and bifidobacteria with elevated aerobe to anaerobe ratios). ${ }^{74-76}$ Given the recognized role of intestinal microbiota in the stimulation of the immune system, ${ }^{77}$ these observations are of potential importance for the identification of pathways of intestinal and systemic immune activation in IBS patients. This field is rapidly growing and takes now advantage of high throughput culture-independent molecular techniques. These methods eliminate the bias of missing the vast majority of intestinal microbiota. Results so far published hold promises for the identification of a potential factor involved in the abnormal stimulation of mucosal immune system.

\section{Implications of Immune Activation for Symptom Perception}

Several correlations between immune activation and IBS symptoms have been described, although remain incompletely clarified (Table). Some studies were underpowered by inclusion of limited number of patients and controls. In addition, correlation coefficients were sometimes weak. However, it is interesting to note that positive correlations have been found between the number of colonic mast cells and abdominal pain ${ }^{51}$ or bloating $^{32}$ and between blood $\mathrm{T}$ cells and bowel habit dissatisfaction as well as global IBS symptoms. ${ }^{78}$ The correlation of blood TNF- $\alpha$ with anxiety and mucosal mast cells with fatigue and depression sug- 
Table. Correlation of Immune Activation With Irritable Bowel Syndrome Symptoms

\begin{tabular}{|c|c|c|c|c|c|c|}
\hline Patients (n) & Immune factor & Site & Symptoms & Correlation & $P$-value & Author \\
\hline 23 & Mast cells & Colon & Abdominal pain & $r=0.47$ & $P=0.004$ & Akbar et al, ${ }^{51} 2008$ \\
\hline 44 & & & Abdominal pain & None & $P>0.05$ & Barbara et al, ${ }^{47} 2004$ \\
\hline 48 & & & Addominal pain & None & $P>0.05$ & Cremon et al, ${ }^{32} 2009$ \\
\hline 48 & & & Abdominal bloating & $r=0.39$ & $P=0.022$ & Cremon et al, 2009 \\
\hline 20 & Mast cells & Jejunum & Global GI symptoms & None & $P>0.05$ & Guilarte, ${ }^{44} 2008$ \\
\hline 44 & Mast cells close to nerves & Colon & Abdominal pain & $\mathrm{r}=0.75$ & $P=0.001$ & Barbara, ${ }^{47} 2004$ \\
\hline 50 & Mast cells & Colon & Fatigue & $r=0.64$ & $P=0.0001$ & Piche et al, ${ }^{52} 2008$ \\
\hline & & & Depression & $r=0.29$ & $P=0.03$ & \\
\hline 74 & $\mathrm{~T}$ cells & Blood & $\begin{array}{l}\text { Bowel habit dissatisfaction } \\
\text { Global IBS symptoms }\end{array}$ & $\begin{array}{l}r=0.30 \\
r=0.29\end{array}$ & $\begin{array}{l}P=0.02 \\
P=0.02\end{array}$ & $\begin{array}{l}\text { Ohman et al, }{ }^{78} 2009 \\
\text { Ohman et al, }{ }^{78} 2009\end{array}$ \\
\hline 74 & $\mathrm{~B}$ cells & Blood & IBS symptoms & None & $P>0.05$ & Ohman et al, ${ }^{78} 2009$ \\
\hline 55 & TNF- $\alpha$ release & Serum & Anxiety & $\mathrm{r}=0.59$ & $P=0.001$ & Liebregts et al, ${ }^{40} 2007$ \\
\hline 38 & Proteases & Feces & IBS symptoms, diarrhea & None & $P>0.05$ & Róka et al, ${ }^{58} 2007$ \\
\hline 51 & Mucosal permeability & Colon & Abdominal pain & $r=0.65$ & $P=0.01$ & Piche et al, ${ }^{9} 2009$ \\
\hline
\end{tabular}

GI, gastrointestinal; IBS, irritable bowel syndrome.

gests the relevance of psychological factors and the brain-gut axis in IBS. A strong significant correlation has been repeatedly found between increased mucosal permeability and abdominal pain, 9,79 further supporting the hypothesis that a barrier defect is of key importance for the activation of mucosal immune responses and related stimulation of pain pathways. So far, the strongest association reported relates to the number of mast cells found in close proximity to nerves with the frequency and severity of abdominal pain $(r=0.70$ and 0.75$) .{ }^{47}$ These findings suggest the contribution of the interactions of mucosal immune cells (ie, mast cells) with the neural network conveying information to the central nervous system to abdominal pain perception.

\section{Are Immune Factors Useful Biomarkers in Clinical Practice?}

The identification of measurable, objective biological factors associated with IBS has generated considerable interest for the "discovery" of a reliable biomarker useful to overcome the limitations of current symptom-based definitions in daily clinical practice, expand the knowledge of pathophysiology and facilitate the development of novel therapeutic interventions (for review, see references $\left.{ }^{80,81}\right)$. Patients could also benefit from the identification of biomarkers to shake themselves off the label of "apprehensive," otherwise healthy individuals with "an imaginary disease." In addition, the possibility to measure biological mediators non-invasively (blood or fecal samples) has increased the appeal for biomarker discovery. Unfortunately, the immunological biomarkers so far described show wide overlap with controls and in- creased levels of pro-inflammatory cytokines have been detected also in patients with other functional GI disorders ${ }^{42}$ or depression, ${ }^{82}$ suggesting poor sensitivity and specificity. ${ }^{80}$ On the other hand more invasive studies (eg, mast cells in proximity to nerve endings) may well correlate with symptoms but are difficult to perform, requiring cumbersome laboratory techniques, confining their value for research rather than clinical practice. Despite these limitations, the biological basis of symptom generation are being recognized in subgroups of patients with IBS paving the way for the identification of one, or more likely more than one, IBS biomarkers. ${ }^{80}$

\section{Therapeutic Implications}

Conceptually, drugs inhibiting intestinal immune activation would provide an excellent proof for implication of immune mechanisms in IBS pathophysiology and symptom generation. In a small controlled trial Dunlop et $\mathrm{al}^{83}$ tested the efficacy of oral prednisolone $(30 \mathrm{mg} / \mathrm{day})$ in patients with post-infectious IBS. Mucosal $\mathrm{T}$ cell counts decreased but this was not accompanied by symptomatic improvement of abdominal pain, diarrhea, frequency or urgency. ${ }^{83}$ Although these results may be viewed as a proof against the role of immune factors in symptom perception in patients with post-infectious IBS, the short duration of treatment and a relatively small steroid dosage could represent potential limiting factors responsible for negative results. Whether a longer course of topical steroids could be more effective remains undetermined.

The use of chromones (mast cell stabilizers) in patients with 
IBS dates back to the ' 80 s when a significant $40 \%$ symptomatic improvement over control was shown in a small cohort of IBS patients. ${ }^{84}$ Other studies have provided evidence of improvement of abdominal pain and diarrhea in IBS over placebo ${ }^{85}$ or elimination diet. ${ }^{86}$ There are limitation of these studies related to the small sample size and the suboptimal trial design (eg, uncontrolled, unblinded design in some studies, crossover design, short term treatment duration or lack of follow-up). Novel trials of chromones are now under way and we await the results with interest.

In a proof-of-concept randomized, double-blind, placebocontrolled trial, we have recently evaluated the potential of 5 -aminosalicylic acid (mesalazine, $800 \mathrm{mg} 3$ times daily for 8 weeks) on intestinal immune cells and symptom perception in patients with IBS. ${ }^{87}$ Compared with placebo, mesalazine significantly reduced mucosal immune cells with a marked suppressive effect on mast cells. Although the study was underpowered for the assessment of symptoms, we detected a significantly improvement of general well being and abdominal pain, although the latter did not reach statistical significance. These data are in agreement with other preliminary uncontrolled trials showing that mesalazine reduced pain and stool frequency and improved stool consistency in patients with post-infectious IBS or non-specific IBS. ${ }^{88-90}$ Further larger studies are now required to test the efficacy of mesalazine on IBS symptoms.

The intestinal microbiota has been the target of different approaches including prebiotics, probiotics, synbiotics, non-absorbable and systemic antibiotics. ${ }^{62}$ A number of mechanisms of action make probiotics very attractive for the treatment of IBS. These include their beneficial effects on gut inflammation, intestinal barrier function and inhibitory effects on visceral hypersensitivity. In general, numerous randomized, placebo-controlled trials have demonstrated improvement in flatulence, abdominal distension and composite IBS symptoms scores (for review, see references ${ }^{62,91}$ ). However, to date there is only limited evidence suggesting that probiotics exert their beneficial effects by modulating immune function in patients with IBS. In a well designed study, O'Mahony et $\mathrm{al}^{92}$ showed that Bifidobacterium infantis 35624, but not Lactobacillus salivarius, was able to reduce systemic pro-inflammatory cytokine profile along with symptom improvement.

\section{Conclusions and Future Perspectives}

Several lines of evidence support the implication of a systemic or intestinal immune activation in IBS patients. Initial data obtained in pilot studies suggest that the immune system could be an interesting and novel target. However, further studies in larger samples are now needed to clarify the importance of these mild abnormalities for symptom generation and the role of anti-inflammatory therapies in patients with IBS.

\section{References}

1. Longstreth GF, Thompson WG, Chey WD, Houghton LA, Mearin F, Spiller RC. Functional bowel disorders. Gastroenterology 2006;130:1480-1491.

2. Barbara G, De Giorgio R, Stanghellini V, Cremon C, Salvioli B, Corinaldesi R. New pathophysiological mechanisms in irritable bowel syndrome. Aliment Pharmacol Ther 2004;20(suppl 2):1-9.

3. Celsus AC. De Medicina, praef. iii. 4.

4. Rather LJ. Disturbance of function (functio laesa): the legendary fifth cardinal sign of inflammation, added by Galen to the four cardinal signs of Celsus. Bull N Y Acad Med 1971;47:303-322.

5. Cenac N, Andrews CN, Holzhausen M, et al. Role for protease activity in visceral pain in irritable bowel syndrome. J Clin Invest 2007;117:636-647.

6. Barbara G, Wang B, Stanghellini V, et al. Mast cell-dependent excitation of visceral-nociceptive sensory neurons in irritable bowel syndrome. Gastroenterology 2007;132:26-37.

7. Gecse K, Róka R, Ferrier L, et al. Increased faecal serine protease activity in diarrhoeic IBS patients: a colonic lumenal factor impairing colonic permeability and sensitivity. Gut 2008;57:591-599.

8. Buhner S, Li Q, Vignali S, et al. Activation of human enteric neurons by supernatants of colonic biopsy specimens from patients with irritable bowel syndrome. Gastroenterology 2009;137:1425-1434.

9. Piche T, Barbara G, Aubert P, et al. Impaired intestinal barrier integrity in the colon of patients with irritable bowel syndrome: involvement of soluble mediators. Gut 2009;58:196-201.

10. Barbara G, Stanghellini V, Cremon C, et al. Aminosalicylates and other anti-inflammatory compounds for irritable bowel syndrome. Dig Dis 2009;27(suppl 1):115-121.

11. Spiller R, Garsed K. Postinfectious irritable bowel syndrome. Gastroenterology 2009;136:1979-1988.

12. Thabane M, Kottachchi DT, Marshall JK. Systematic review and meta-analysis: The incidence and prognosis of post-infectious irritable bowel syndrome. Aliment Pharmacol Ther 2007;26:535-544.

13. Marshall JK, Thabane M, Garg AX, et al. Intestinal permeability in patients with irritable bowel syndrome after a waterborne outbreak of acute gastroenteritis in Walkerton, Ontario. Aliment Pharmacol Ther 2004;20:1317-1322.

14. Marshall JK, Thabane M, Garg AX, et al. Incidence and epidemiology of irritable bowel syndrome after a large waterborne outbreak of bacterial dysentery. Gastroenterology 2006;131:445-450.

15. Dunlop SP, Jenkins D, Neal KR, Spiller RC. Relative importance of enterochromaffin cell hyperplasia, anxiety, and depression in postinfectious IBS. Gastroenterology 2003;125:1651-1659.

16. Villani AC, Lemire M, Thabane M, et al. Genetic risk factors for post-infectious irritable bowel syndrome following a waterborne out- 
break of gastroenteritis. Gastroenterology 2010;138:1502-1513.

17. Spiller RC, Jenkins D, Thornley JP, et al. Increased rectal mucosal enteroendocrine cells, T lymphocytes, and increased gut permeability following acute Campylobacter enteritis and in post-dysenteric irritable bowel syndrome. Gut 2000;47:804-811.

18. Wang LH, Fang XC, Pan GZ. Bacillary dysentery as a causative factor of irritable bowel syndrome and its pathogenesis. Gut 2004;53: 1096-1101.

19. Dunlop SP, Jenkins D, Spiller RC. Distinctive clinical, psychological, and histological features of postinfective irritable bowel syndrome. Am J Gastroenterol 2003;98:1578-1583.

20. Limsui D, Pardi DS, Camilleri M, et al. Symptomatic overlap between irritable bowel syndrome and microscopic colitis. Inflamm Bowel Dis 2007;13:175-181.

21. Isgar B, Harman M, Kaye MD, Whorwell PJ. Symptoms of irritable bowel syndrome in ulcerative colitis in remission. Gut 1983;24:190192.

22. Simrén M, Axelsson J, Gillberg R, Abrahamsson H, Svedlund J, Björnsson ES. Quality of life in inflammatory bowel disease in remission: the impact of IBS-like symptoms and associated psychological factors. Am J Gastroenterol 2002;97:389-396.

23. Farrokhyar F, Marshall JK, Easterbrook B, Irvine EJ. Functional gastrointestinal disorders and mood disorders in patients with inactive inflammatory bowel disease: prevalence and impact on health. Inflamm Bowel Dis 2006;12:38-46.

24. Dunlop SP, Hebden J, Campbell E, et al. Abnormal intestinal permeability in subgroups of diarrhea-predominant irritable bowel syndromes. Am J Gastroenterol 2006;101:1288-1294.

25. O'Leary C, Wieneke P, Buckley S, et al. Celiac disease and irritable bowel-type symptoms. Am J Gastroenterol 2002;97:1463-1467.

26. Midhagen G, Hallert C. High rate of gastrointestinal symptoms in celiac patients living on a gluten-free diet: controlled study. Am J Gastroenterol 2003;98:2023-2026.

27. Frissora CL, Koch KL. Symptom overlap and comorbidity of irritable bowel syndrome with other conditions. Curr Gastroenterol Rep 2005;7:264-271.

28. Eneström S, Bengtsson A, Frödin T. Dermal IgG deposits and increase of mast cells in patients with fibromyalgia - relevant findings or epiphenomena? Scand J Rheumatol 1997;26:308-313.

29. Sant GR, Kempuraj D, Marchand JE, Theoharides TC. The mast cell in interstitial cystitis: role in pathophysiology and pathogenesis. Urology 2007;69(4 suppl):34-40.

30. Bornstein J, Goldschmid N, Sabo E. Hyperinnervation and mast cell activation may be used as histopathologic diagnostic criteria for vulvar vestibulitis. Gynecol Obstet Invest 2004;58:171-178.

31. Ohman L, Isaksson S, Lundgren A, Simrén M, Sjövall H. A controlled study of colonic immune activity and beta7+ blood T lymphocytes in patients with irritable bowel syndrome. Clin Gastroenterol Hepatol 2005;3:980-986.

32. Cremon C, Gargano L, Morselli-Labate AM, et al. Mucosal immune activation in irritable bowel syndrome: gender-dependence and association with digestive symptoms. Am J Gastroenterol 2009;104: 392-400.

33. Chadwick VS, Chen W, Shu D, et al. Activation of the mucosal immune system in irritable bowel syndrome. Gastroenterology 2002; 122:1778-1783.
34. Holmén N, Isaksson S, Simrén M, Sjövall H, Ohman L. CD4+ $\mathrm{CD} 25+$ regulatory $\mathrm{T}$ cells in irritable bowel syndrome patients. Neurogastroenterol Motil 2007;19:119-125.

35. Forshammar J, Isaksson S, Strid H, et al. A pilot study of colonic B cell pattern in irritable bowel syndrome. Scand J Gastroenterol 2008;43:1461-1466.

36. Schoepfer AM, Schaffer T, Seibold-Schmid B, Müller S, Seibold F. Antibodies to flagellin indicate reactivity to bacterial antigens in IBS patients. Neurogastroenterol Motil 2008;20:1110-1118.

37. O'Sullivan M, Clayton N, Breslin NP, et al. Increased mast cells in the irritable bowel syndrome. Neurogastroenterol Motil 2000;12: 449-457.

38. Dinan TG, Clarke G, Quigley EM, et al. Enhanced cholinergicmediated increase in the pro-inflammatory cytokine IL-6 in irritable bowel syndrome: role of muscarinic receptors. Am J Gastroenterol 2008;103:2570-2576.

39. Dinan TG, Quigley EM, Ahmed SM, et al. Hypothalamic-pituitary-gut axis dysregulation in irritable bowel syndrome: plasma cytokines as a potential biomarker? Gastroenterology 2006;130:304-311.

40. Liebregts T, Adam B, Bredack C, et al. Immune activation in patients with irritable bowel syndrome. Gastroenterology 2007;132: 913-920.

41. Elsenbruch S, Holtmann G, Oezcan D, et al. Are there alterations of neuroendocrine and cellular immune responses to nutrients in women with irritable bowel syndrome? Am J Gastroenterol 2004;99:703710.

42. Kindt S, Van Oudenhove L, Broekaert D, et al. Immune dysfunction in patients with functional gastrointestinal disorders. Neurogastroenterol Motil 2009;21:389-398.

43. Aerssens J, Camilleri M, Talloen W, et al. Alterations in mucosal immunity identified in the colon of patients with irritable bowel syndrome. Clin Gastroenterol Hepatol 2008;6:194-205.

44. Guilarte M, Santos J, de Torres I, et al. Diarrhoea-predominant IBS patients show mast cell activation and hyperplasia in the jejunum. Gut 2007;56:203-209.

45. Weston AP, Biddle WL, Bhatia PS, Miner PB Jr. Terminal ileal mucosal mast cells in irritable bowel syndrome. Dig Dis Sci 1993;38: 1590-1595.

46. Walker MM, Talley NJ, Prabhakar M, et al. Duodenal mastocytosis, eosinophilia and intraepithelial lymphocytosis as possible disease markers in the irritable bowel syndrome and functional dyspepsia. Aliment Pharmacol Ther 2009;29:765-773.

47. Barbara G, Stanghellini V, De Giorgio R, et al. Activated mast cells in proximity to colonic nerves correlate with abdominal pain in irritable bowel syndrome. Gastroenterology 2004;126:693-702.

48. Macsharry J, O'Mahony L, Fanning A, et al. Mucosal cytokine imbalance in irritable bowel syndrome. Scand J Gastroenterol 2008;43: 1467-1476.

49. Chey WD, Nojkov B, Rubenstein JH, Dobhan RR, Greenson JK, Cash BD. The yield of colonoscopy in patients with non-constipated irritable bowel syndrome: results from a prospective, controlled US trial. Am J Gastroenterol 2010;105:859-865.

50. Barbara G, Stanghellini V, De Giorgio R, Corinaldesi R. Functional gastrointestinal disorders and mast cells: implications for therapy. Neurogastroenterol Motil 2006;18:6-17.

51. Akbar A, Yiangou Y, Facer P, Walters JR, Anand P, Ghosh S. 
Increased capsaicin receptor TRPV1-expressing sensory fibres in irritable bowel syndrome and their correlation with abdominal pain. Gut 2008;57:923-929.

52. Piche T, Saint-Paul MC, Dainese R, et al. Mast cells and cellularity of the colonic mucosa correlated with fatigue and depression in irritable bowel syndrome. Gut 2008;57:468-473.

53. Macfarlane GT, Allison C, Gibson SA, Cummings JH. Contribution of the microflora to proteolysis in the human large intestine. $\mathrm{J}$ Appl Bacteriol 1988;64:37-46.

54. Schuurs AH, Verheul HA. Effects of gender and sex steroids on the immune response. J Steroid Biochem 1990;35:157-172.

55. Stead RH, Dixon MF, Bramwell NH, Riddell RH, Bienenstock J. Mast cells are closely apposed to nerves in the human gastrointestinal mucosa. Gastroenterology 1989;97:575-585.

56. Wang LH, Fang XC, Pan GZ. Bacillary dysentery as a causative factor of irritable bowel syndrome and its pathogenesis. Gut 2004;53: 1096-1101.

57. Schemann M, Michel K, Ceregrzyn M, Zeller F, Seidl S, Bischoff SC. Human mast cell mediator cocktail excites neurons in human and guinea-pig enteric nervous system. Neurogastroenterol Motil 2005;17:281-289.

58. Róka R, Rosztóczy A, Leveque M, et al. A pilot study of fecal serine-protease activity: a pathophysiologic factor in diarrhea-predominant irritable bowel syndrome. Clin Gastroenterol Hepatol 2007;5: 550-555.

59. Ossovskaya VS, Bunnett NW. Protease-activated receptors: contribution to physiology and disease. Physiol Rev 2004;84:579-621.

60. Park MI, Camilleri M. Is there a role of food allergy in irritable bowel syndrome and functional dyspepsia? A systematic review. Neurogastroenterol Motil 2006;18:595-607.

61. Taché Y, Bonaz B. Corticotropin-releasing factor receptors and stress-related alterations of gut motor function. J Clin Invest 2007; 117:33-40.

62. Barbara G, Stanghellini V, Cremon C, et al. Probiotics and irritable bowel syndrome: rationale and clinical evidence for their use. J Clin Gastroenterol 2008;42(suppl 3 Pt 2):S214-S217.

63. Camilleri M, Nadeau A, Tremaine WJ, et al. Measurement of serum 7alpha-hydroxy-4-cholesten-3-one (or 7alphaC4), a surrogate test for bile acid malabsorption in health, ileal disease and irritable bowel syndrome using liquid chromatography-tandem mass spectrometry. Neurogastroenterol Motil 2009;21:734-e43.

64. Tanaka Y, Kanazawa M, Fukudo S, Drossman DA. Biopsychosocial model of irritable bowel syndrome. J Neurogastroenterol Motil 2011;17:131-139.

65. Kiecolt-Glaser JK, McGuire L, Robles TF, Glaser R. Psychoneuroimmunology and psychosomatic medicine: back to the future. Psychosom Med 2002;64:15-28.

66. Fukudo S, Nomura T, Hongo M. Impact of corticotropin-releasing hormone on gastrointestinal motility and adrenocorticotropic hormone in normal controls and patients with irritable bowel syndrome. Gut 1998;42:845-849.

67. Fukudo S. Role of corticotropin-releasing hormone in irritable bowel syndrome and intestinal inflammation. J Gastroenterol 2007;42 (suppl 17):48-51.

68. Van der Veek PP, van den Berg M, de Kroon YE, Verspaget HW, Masclee AA. Role of tumor necrosis factor-alpha and interleukin-10 gene polymorphisms in irritable bowel syndrome. Am J Gastroenterol 2005;100:2510-2516.

69. Gonsalkorale WM, Perrey C, Pravica V, Whorwell PJ, Hutchinson IV. Interleukin 10 genotypes in irritable bowel syndrome: evidence for an inflammatory component? Gut 2003;52:91-93.

70. Porras M, Martín MT, Yang PC, Jury J, Perdue MH, Vergara P. Correlation between cyclical epithelial barrier dysfunction and bacterial translocation in the relapses of intestinal inflammation. Inflamm Bowel Dis 2006;12:843-852.

71. Preidis GA, Versalovic J. Targeting the human microbiome with antibiotics, probiotics, and prebiotics: gastroenterology enters the metagenomics era. Gastroenterology 2009;136:2015-2031.

72. Moayyedi P, Ford AC, Talley NJ, et al. The efficacy of probiotics in the treatment of irritable bowel syndrome: a systematic review. Gut 2010;59:325-332.

73. Pimentel M, Lembo A, Chey WD, et al. Rifaximin therapy for patients with irritable bowel syndrome without constipation. N Engl J Med 2011;364:22-32.

74. Lyra A, Rinttilä T, Nikkilä J, et al. Diarrhoea-predominant irritable bowel syndrome distinguishable by $16 \mathrm{~S}$ rRNA gene phylotype quantification. World J Gastroenterol 2009;15:5936-5945.

75. Kassinen A, Krogius-Kurikka L, Mäkivuokko H, et al. The fecal microbiota of irritable bowel syndrome patients differs significantly from that of healthy subjects. Gastroenterology 2007;133:24-33.

76. Malinen E, Rinttilä T, Kajander K, et al. Analysis of the fecal microbiota of irritable bowel syndrome patients and healthy controls with real-time PCR. Am J Gastroenterol 2005;100:373-382.

77. Round JL, Mazmanian SK. The gut microbiota shapes intestinal immune responses during health and disease. Nat Rev Immunol 2009; 9:313-323.

78. Ohman L, Isaksson S, Lindmark AC, et al. T-cell activation in patients with irritable bowel syndrome. Am J Gastroenterol 2009;104: 1205-1212.

79. Zhou Q, Zhang B, Verne GN. Intestinal membrane permeability and hypersensitivity in the irritable bowel syndrome. Pain 2009;146:4146.

80. Barbara G, Stanghellini V. Biomarkers in IBS: when will they replace symptoms for diagnosis and management? Gut 2009;58:1571-1575.

81. Clarke G, Quigley EM, Cryan JF, Dinan TG. Irritable bowel syndrome: towards biomarker identification. Trends Mol Med 2009; $15: 478-489$.

82. Howren MB, Lamkin DM, Suls J. Associations of depression with C-reactive protein, IL-1, and IL-6: a meta-analysis. Psychosom Med 2009;71:171-186.

83. Dunlop SP, Jenkins D, Neal KR, et al. Randomized, double-blind, placebo-controlled trial of prednisolone in post-infectious irritable bowel syndrome. Aliment Pharmacol Ther 2003;18:77-84.

84. Bolin TD. Use of oral sodium cromoglycate in persistent diarrhoea. Gut 1980;21:848-850.

85. Lunardi C, Bambara LM, Biasi D, et al. Double-blind cross-over trial of oral sodium cromoglycate in patients with irritable bowel syndrome due to food intolerance. Clin Exp Allergy 1991;21:569-572.

86. Stefanini GF, Saggioro A, Alvisi V, et al. Oral cromolyn sodium in comparison with elimination diet in the irritable bowel syndrome, diarrheic type: multicenter study of 428 patients. Scand J Gastroenterol 1995;30:535-541. 
87. Corinaldesi R, Stanghellini V, Cremon C, et al. Effect of mesalazine on mucosal immune biomarkers in irritable bowel syndrome: a randomized controlled proof-of-concept study. Aliment Pharmacol Ther 2009;30:245-252

88. Bafutto M, Almeida JR, Leite NV, Filho JR. Treatment of diarrhea-predominant irritable bowel syndrome with mesalazine and/or Saccharomyces boulardii. Gastroenterology 2008;134(suppl 1):A527.

89. Bafutto M, Almeida JR, Almeida RC, Almeida TC, Leite NV, Filho JR. Treatment of post-infectious irritable bowel syndrome and non infective irritable bowel syndrome with mesalazine. Gastroenterology 2008;134(suppl 1):A672.

90. Andrews CN, Petcu R, Griffiths T, et al. Mesalamine alters colonic mucosal proteolytic activity and fecal bacterial profiles in diarrhea-predominant irritable bowel syndrome (IBS-D). Gastroenterology 2008;134(suppl 1):A548.

91. Spiller R. Review article: probiotics and prebiotics in irritable bowel syndrome. Aliment Pharmacol Ther 2008;28:385-396.

92. O'Mahony L, McCarthy J, Kelly P, et al. Lactobacillus and Bifidobacterium in irritable bowel syndrome: symptom responses and relationship to cytokine profiles. Gastroenterology 2005;128:541-551. 